\title{
Increased risk of obstructive pulmonary disease in tunnel workers
}

Bente Ulvestad, Berit Bakke, Erik Melbostad, ^ Per Fuglerud, Johny Kongerud, May Brit Lund

\begin{abstract}
Background-Tunnel workers are exposed to gases and particles from blasting and diesel exhausts. The aim of this study was to assess the occurrence of respiratory symptoms and airflow limitation in tunnel workers and to relate these findings to years of exposure.

Methods-Two hundred and twelve tunnel workers and a reference group of 205 other heavy construction workers participated in a cross sectional investigation. Exposure measurements were carried out to demonstrate the difference in exposure between the two occupational groups. Spirometric tests and a questionnaire on respiratory symptoms and smoking habits were applied. Atopy was determined by a multiple radioallergosorbent test (RAST). Radiological signs of silicosis were evaluated. Respiratory symptoms and lung function were studied in relation to years of exposure and adjusted for smoking habits and atopy.
\end{abstract}

Results-Compared with the reference subjects the tunnel workers had a significant decrease in forced vital capacity (FVC) \% predicted and forced expiratory volume in one second $\left(\mathrm{FEV}_{1}\right) \%$ predicted when related to years of exposure. Adjusted $\mathrm{FEV}_{1}$ decreased by $17 \mathrm{ml}$ for each year of tunnel work exposure compared with $0.5 \mathrm{ml}$ in outdoor heavy construction workers. The tunnel workers also reported significantly higher occurrence of respiratory symptoms. The prevalence of chronic obstructive pulmonary disease (COPD) was $14 \%$ in the tunnel workers compared with $8 \%$ in the reference subjects.

Conclusion-Exposure to dust and gases from diesel exhaust, blasting, drilling and rock transport in tunnel work enhances the risk for accelerated decline in $\mathrm{FEV}_{1}$, respiratory symptoms, and COPD in tunnel workers compared with other heavy construction workers.

(Thorax 2000;55:277-282)

Keywords: chronic obstructive pulmonary disease; lung function; occupational disease; diesel exhausts; $\alpha$-quartz

Dr B Ulvestad, Selmer ASA,

P B1175 Sentrum, N-0107

Oslo, Norway

email: bente.ulvestad@

selmer.no

Received 3 September 1999 Returned to authors
16 November 1999

Revised manuscript received

21 December 1999

Accepted for publication

7 January 2000
Tunnelling is a common feature of heavy construction work in Norway. In 1998, 875 new tunnel kilometres were excavated. The technology of tunnel excavation has developed rapidly during recent years. Currently used methods apply large high powered machines at high working intensity. Considerable amounts of diesel exhausts are emitted in addition to other pollutants such as gases and dust from blasting. ${ }^{12}$

It is known that construction workers have an increased risk of mesothelioma, ${ }^{3}$ on-site trauma, ${ }^{4}$ musculoskeletal injury, ${ }^{5}$ and dermatitis, ${ }^{6}$ but whether they also have an increased risk of work related chronic obstructive pulmonary disease (COPD) has not been clearly established. ${ }^{78}$ In a cross sectional study "non-specific chronic lung disease" was reported to occur more frequently in nonsmoking older construction workers than in their non-smoking blue collar counterparts, and this higher occurrence of chronic lung disease was ascribed to dust exposure. ${ }^{9}$ However, the study did not distinguish between the various job categories within construction work. In a Norwegian cross sectional study of men aged 30-46 years with occupational exposure to $\alpha$-quartz and normal chest radiographs, the duration of exposure was shown to be an independent predictor of spirometric airflow limitation. ${ }^{10}$ However, tunnel workers constituted just one of many working groups assumed to be exposed to $\alpha$-quartz and quantitative exposure assessments were not carried out.

Diesel exhaust has been reported to give inflammatory and antioxidant responses in the airways, ${ }^{11}$ as well as airways obstruction. ${ }^{12}$ Decreased lung function after exposure to nitrogen dioxide $\left(\mathrm{NO}_{2}\right)$ has also been reported. ${ }^{13}$ A study of machine shop workers concluded that occupational asthma due to oil mists was common. ${ }^{14}$ Tunnel workers are heavily exposed to all the above mentioned pollutants ( $\alpha$-quartz and other particles from blasting, diesel exhausts, $\mathrm{NO}_{2}$ and oil mist), but to our knowledge no previous study has described the relationship between COPD and tunnel work. The principal aim of this study was to assess the occurrence of respiratory symptoms and airflow limitation in tunnel workers and to relate these findings to years of exposure.

\section{Methods}

SUBJECTS

All tunnel and other heavy construction workers $(n=417)$ employed at 15 work sites were invited to participate in a cross sectional study. The medical tests were carried out at the work sites and the health service team returned to the sites several times until the attendance rate was $100 \%$. The study group consisted of 212 male tunnel workers (tunnel face workers, shotcreters and concrete workers) who lived at 
Table 1 Clinical characteristics of 212 tunnel workers and 205 outdoor construction workers

\begin{tabular}{|c|c|c|}
\hline Variable & $\begin{array}{l}\text { Tunnel workers } \\
(n=212)\end{array}$ & $\begin{array}{l}\text { Construction } \\
\text { workers }(n=205)\end{array}$ \\
\hline Age (years) ${ }^{\star}$ & $41(10)$ & $40(11)$ \\
\hline Height $(\mathrm{cm})^{\star}$ & $180(6)$ & $179(6)$ \\
\hline Years of employment ${ }^{\star}$ & $13(9)$ & $17(9)$ \\
\hline$<10$ years $\dagger$ & $84(40)$ & $48(23)$ \\
\hline $10-20$ years $\dagger$ & $95(45)$ & $90(44)$ \\
\hline$>20$ years $\dagger$ & $33(15)$ & $67(33)$ \\
\hline \multicolumn{3}{|l|}{ Smoking status $\dagger$} \\
\hline Never smoked & $59(28)$ & $64(31)$ \\
\hline Former smokers & $39(18)$ & $34(17)$ \\
\hline Current smokers & $114(54)$ & $107(52)$ \\
\hline Pack years ${ }^{\star}$ & $16(13)$ & $14(10)$ \\
\hline Phadiatop positive $†$ & $34(16)$ & $27(13)$ \\
\hline
\end{tabular}

a camp for two weeks and then stayed home for one week. They worked 10 hour shifts with two breaks of 30 minutes each. The study group was compared with a reference group comprising 205 heavy construction workers (carpenters and iron fixers) who worked in the open, but otherwise had the same working schedule as the tunnel workers. None of the heavy construction workers had previously worked in tunnelling. Demographic data of the study subjects are given in table 1 . The study was approved by the National Data Inspectorate and the Regional Medical Board of Ethics.

\section{EXPOSURE}

Fob description

The excavation of tunnels is intensive and demanding. The workers are skilled and physically fit. In addition to operating large drilling machinery and blasting, the tunnel workers perform a variety of other jobs. The work normally follows this sequence: (1) drilling holes for placing the explosives, (2) blasting, (3) loading debris onto trucks or mining cars which are pulled by diesel locomotives and transported out of the tunnel. The support work includes fastening the unsafe rock with steel bolts, covering the rock with a concrete layer by shotcreting or by casting a concrete lining. Tunnels longer than about $200 \mathrm{~m}$ are usually mechanically ventilated during excavation. Fresh air is supplied through a flexible ventilation duct from a fan outside the tunnel to the tunnel face where the blasting crew works. In most cases the blast cloud is dispersed through the tunnel cavity.

\section{Sampling methods}

Measurements were carried out on 15 construction projects during a three year period between 1996 and 1999. A total of 193 workers

Table 2 Prevalences (percentages) of respiratory symptoms in tunnel workers and outdoor construction workers

\begin{tabular}{lllll}
\hline Respiratory symptoms & $\begin{array}{l}\text { Tunnel workers } \\
(n=212)\end{array}$ & $\begin{array}{l}\text { Construction } \\
\text { workers } \\
(n=205)\end{array}$ & OR & 95\% CIt \\
\hline Morning cough & $65(30)$ & $55(27)$ & 1.08 & 0.68 to 1.72 \\
Cough during the day & $37(17)$ & $23(11)$ & 1.94 & 1.25 to 5.79 \\
Shortness of breath on exercise & $50(23)$ & $20(10)$ & 3.47 & 1.96 to 6.45 \\
Chest tightness and wheezing & $56(26)$ & $27(13)$ & 2.56 & 1.51 to 4.42 \\
\hline
\end{tabular}

${ }^{\star}$ OR adjusted for years in the same job (<10years, 10-20 years, $>20$ years), atopy, and smoking (never, current/former) by logistic regression.

$+95 \%$ confidence limits of the odds ratio. (tunnel and construction workers) participated in the exposure assessments. Respirable and total dust, oil mist, and inorganic gases were collected by personal sampling. The persons to carry the samplers were chosen at random, as were the days when sampling was carried out.

Total dust was collected on acryl copolymer membrane filters (type Versapore 800) with pore size $0.8 \mu \mathrm{m}$ in $25 \mathrm{~mm}$ aerosol filter cassettes (type Gelman) with a sampling flow rate of $2.01 / \mathrm{min}$. Respirable dust was collected on $37 \mathrm{~mm}$ cellulose acetate filters with a pore size of $0.8 \mu \mathrm{m}$ in Casella cyclones with a sampling flow rate of $2.2 \mathrm{l} / \mathrm{min}$. The sampling time varied from five to seven hours and was assumed to be representative of the 10 hour shift. The amount of dust collected was measured by gravimetric analysis. The determination of silica in the respirable fraction was analysed by $x$ ray diffraction. Oil mist was collected on glass fibre filters (type Whatman GF (A)) and cellulose acetate filters with a pore size of $0.8 \mu \mathrm{m}$ in $37 \mathrm{~mm}$ aerosol cassettes (type Millipore).The sampling time varied from two to four hours. Oil mist was analysed by Fourier transform infrared spectroscopy after desorption with Freon 113.

$\mathrm{NO}_{2}$ was measured by direct reading instruments, electrochemical sensors with a data logging facility built into the instrument (type Neotox-xl personal single gas monitor, Neotronics Limited, Takeley, UK). A sampling rate of one reading every second minute was selected. The sensors were calibrated every second month with gases of known concentrations.

\section{ASSESSMENT OF RESPIRATORY HEALTH EFFECTS}

\section{Questionnaire}

A self-administered questionnaire applied in earlier Norwegian investigations ${ }^{15} 16$ and validated in $1989^{17}$ was used to assess the presence of lower airways symptoms. Questions included physician diagnosed asthma and occurrence of cough, wheeze, chest tightness and shortness of breath (at rest and at exertion). In accordance with diagnostic criteria previously applied in Norwegian population surveys, COPD was diagnosed in those with a history of chronic cough, phlegm when coughing, breathlessness and/or wheezing, and a ratio of forced expiratory volume in one second $\left(\mathrm{FEV}_{1}\right)$ to forced vital capacity (FVC) of less than $0.7 .^{18}$ To categorise smoking habits the subjects were classified as never smokers, former smokers, and smokers. ${ }^{19}$ Former smokers were those who had stopped smoking for more than 12 months (table 1). In current and former smokers the quantitative effect of smoking was measured in pack years. ${ }^{10}$ This was calculated by multiplying the duration of smoking (in years) by the average number of cigarettes smoked daily divided by 20 .

\section{Spirometric tests}

Spirometric measurements were performed in the sitting position with a bellows spirometer (Vitalograph S with PFT2 PLUS printer, Buckingham, UK), operated by the same trained technician. The spirometer was calibrated daily using a three litre syringe. The 
Table 3 Mean (SE) lung function in 212 tunnel workers compared with 205 outdoor construction workers

\begin{tabular}{lrlc}
\hline & $\begin{array}{l}\text { Tunnel workers }\left(n=\begin{array}{l}\text { Construction workers } \\
(n=205)\end{array}\right. \\
\text { 212) }\end{array}$ & $\begin{array}{l}\text { Difference between } \\
\text { construction and tunnel } \\
\text { workerst }\end{array}$ \\
\hline FVC (\% of predicted) & $103.7(1.4)$ & $103.9(1.4)$ & $0.2(-2.9$ to 3.3$)$ \\
$<10$ years employed & $107.1(1.8)$ & $101.9(2.3)$ & $-5.2(-10.6$ to 0.2$)$ \\
$10-20$ years employed & $104.0(1.8)$ & $106.0(1.8)$ & $2.0(-2.4$ to 6.3$)$ \\
$>20$ years employed & $100.0(2.8)$ & $104.0(1.8)$ & $4.0(-2.4$ to 10.2$)$ \\
FEV $_{1}$ (\% of predicted) & $95.5(1.5)$ & $100.6(1.5)$ & $5.1(1.8$ to 8.4$)$ \\
$<10$ years employed & $101.6(2.4)$ & $100.3(2.4)$ & $-1.3(-7.1$ to 4.5$)$ \\
$10-20$ years employed & $94.4(1.9)$ & $101.6(1.9)$ & $7.2(2.5$ to 11.9$)$ \\
$>20$ years employed & $90.3(3.0)$ & $99.8(2.2)$ & $9.5(2.7$ to 16.2$)$ \\
FEV $_{1} \% \star \star$ & $74.7(0.8)$ & $79.6(0.7)$ & $4.9(3.2$ to 6.5$)$ \\
FEF $_{25-75}$ (\% predicted) ${ }^{\star \star}$ & $79.9(2.5)$ & $90.4(2.4)$ & $10.5(4.9$ to 16.1$)$ \\
\hline
\end{tabular}

The means are adjusted for years in the same job ( $<10$ years, 10-20 years, and $>20$ years), atopy (yes, no), and smoking (never, current/former).

$\mathrm{FVC}=$ forced vital capacity; $\mathrm{FEV}_{1}=$ forced expiratory volume in one second; $\mathrm{FEV}_{1} \%=$ $\mathrm{FEV}_{1} / \mathrm{FVC} \times 100 ; \mathrm{FEF}_{25-75}=$ forced expired flow from $25 \%$ to $75 \%$ of $\mathrm{FVC}$.

${ }^{\star} \mathrm{p}<0.05$ for interaction between occupational group and years employed; ${ }^{\star \star} \mathrm{p}<0.001$ for occupational group.

†Mean $(95 \% \mathrm{CI})$.

Table 4 Multiple linear regression models for $\triangle F E V_{1}$ (predicted - observed) in 212 tunnel workers and 205 outdoor construction workers

\begin{tabular}{|c|c|c|c|c|c|c|}
\hline \multirow[b]{2}{*}{ Covariables } & \multicolumn{3}{|c|}{$\triangle F E V_{1}$ (l) in tunnel workers } & \multicolumn{3}{|c|}{$\triangle F E V_{1}$ (l) in construction workers } \\
\hline & $\begin{array}{l}\text { Regression } \\
\text { coefficient }\end{array}$ & $S E$ & $p$ value & $\begin{array}{l}\text { Regression } \\
\text { coefficient }\end{array}$ & $S E$ & p value \\
\hline $\begin{array}{l}\text { Years employed in the } \\
\text { same job }\end{array}$ & -0.017 & 0.005 & 0.001 & -0.0005 & 0.005 & 0.9 \\
\hline $\begin{array}{l}\text { Pack years in cigarette } \\
\text { smokers } \\
\text { Atopy }\end{array}$ & $\begin{array}{l}-0.009 \\
-0.167\end{array}$ & $\begin{array}{l}0.003 \\
0.123\end{array}$ & $\begin{array}{l}0.005 \\
0.173\end{array}$ & $\begin{array}{l}-0.007 \\
-0.048\end{array}$ & $\begin{array}{l}0.004 \\
0.122\end{array}$ & $\begin{array}{l}0.08 \\
0.7\end{array}$ \\
\hline
\end{tabular}

$\mathrm{FEV}_{1}=$ forced expiratory volume in one second.

subject was wearing a nose clip. The measurements were performed in accordance with the guidelines recommended by the American Thoracic Society. ${ }^{20}$ Room and spirometer temperature, as well as barometric pressure, were recorded. Each subject performed at least three preferably identical FVC curves-that is, within a variation of $50 \mathrm{ml}$ or a maximum of $2 \%$. The best $\mathrm{FEV}_{1}$ values were selected for statistical analysis. Two subjects did not complete the spirometric examination. Recorded variables were $\mathrm{FVC},\left(\mathrm{FEV}_{1}\right), \mathrm{FEV}_{1} / \mathrm{FVC} \times 100$ $\left(\mathrm{FEV}_{1} \%\right)$, and forced expired flow from $25 \%$ to $75 \%$ of FVC $\left(\mathrm{FEF}_{25-75}\right)$. The lung function variables were expressed in absolute values and as percentage of predicted using the reference values of the European Coal and Steel Community (ECSC). ${ }^{21}$

\section{IgE measurements}

Venous blood samples were drawn from all subjects. The serum samples were frozen at $-70^{\circ} \mathrm{C}$. Screening for atopic allergy was performed using Phadiatop (Pharmacia Diagnostics AB, Uppsala, Sweden), a multiple RAST (radioallergosorbent test) of IgE against 10 common respiratory allergens (birch, timothy,

Table 5 Determinants of chronic obstructive pulmonary disease (COPD) in heavy construction workers

\begin{tabular}{lll}
\hline Covariables & $O R^{\star}$ & $95 \%$ CI \\
\hline $\begin{array}{l}\text { Occupation group (tunnel worker vs } \\
\text { construction worker) }\end{array}$ & 2.50 & 1.31 to 4.96 \\
$\begin{array}{l}\text { Smoke (current and former vs never) } \\
\text { Years employed }\end{array}$ & 2.55 & 1.16 to 6.43 \\
$\quad 10-20$ vs $<10$ & 2.56 & 1.13 to 6.32 \\
$>20$ vs $10-20$ & 1.54 & 0.74 to 3.14 \\
Atopy (yes vs no) & 1.15 & 0.44 to 2.66 \\
\hline
\end{tabular}

«The odds ratios are adjusted for the other covariates. mugwort, Cladosporium herbarum, Alternaria tenuis, Dermatophagoides pteronyssinus, cat dander, dog epithelium, and horse dander). ${ }^{22}$

\section{Chest radiographs}

Full format chest radiographs were taken in all the tunnel workers and were read "blind" by two independent radiologists. The first reader was a radiologist at the hospital where the chest radiographs were taken and the second reader was a certified International Labour Organisation (ILO) A-reader who used the ILO classification method to evaluate radiological signs of silicosis. ${ }^{23}$

\section{DATA ANALYSIS}

Demographic data were summarised for each occupational group using mean and standard deviation for continuous data and numbers and percentages for categorical data. The relationships between respiratory symptoms (yes/no) and the covariates occupational group, smoking status, years employed in the same job, and atopy (no/yes) were investigated using logistic regression. ${ }^{24}$ The covariate smoking status contained the categories never smoked and former/ current smokers, and the covariate years employed in the same job contained the categories $<10$ years, $10-20$ years and $>20$ years. Two design variables were produced from the covariate years employed in the same job: the first compared $<10$ years with $10-20$ years and the second compared $10-20$ years with $>20$ years.

The following three interaction terms were investigated: occupational group and smoking status, occupational group and years employed in the same job, and occupational group and atopy. The covariate age was not included in the model due to high correlation (above 0.7) with the covariate years employed in the same job. The risk ratio of tunnel versus construction work was estimated by adjusted odds ratio (tunnel/construction) from the regression model including all four covariates. Corresponding $95 \%$ confidence intervals for the adjusted odds ratios were also calculated. The COPD data were analysed in the same way as were respiratory symptoms.

The lung function variables were presented as percentages of the predicted values. The relationships between lung function variables and the covariates occupational group, smoking status, years employed in the same job, and atopy were investigated by means of analysis of variance. ${ }^{25}$ The covariates were categorised in the same way as respiratory symptoms and the same interaction terms were investigated. The difference between tunnel and construction workers was estimated by adjusted mean from the analysis of variance model including all four covariates. Corresponding 95\% confidence intervals for the adjusted mean difference was also calculated. In the case of significant interaction terms the adjusted mean difference was stratified by the significant term.

The relationship between a decrease in $\mathrm{FEV}_{1}$ from the predicted value and years employed in the same job, pack years, and atopy was investigated by means of multiple regression. ${ }^{25}$ The regression coefficients from this model were 
Table 6 Exposure to pollutants in tunnels and outdoor construction work

\begin{tabular}{|c|c|c|c|c|c|c|c|}
\hline \multirow[b]{2}{*}{ Airborne pollutants } & \multirow[b]{2}{*}{$H S$} & \multicolumn{3}{|c|}{ Tunnels } & \multicolumn{3}{|c|}{ Outdoor construction work } \\
\hline & & No. & $G M$ & $95 \% C I^{\star}$ & No. & $G M$ & $95 \% C I^{\star}$ \\
\hline Total dust & $10 \mathrm{mg} / \mathrm{m}^{3}$ & 366 & 3.6 & 3.2 to 4.0 & 32 & 1.05 & 0.85 to 1.29 \\
\hline Respirable dust & $5 \mathrm{mg} / \mathrm{m}^{3}$ & 372 & 1.2 & 1.09 to 1.31 & 37 & 0.21 & 0.18 to 0.25 \\
\hline$\alpha$-quartz & $0.1 \mathrm{mg} / \mathrm{m}^{3}$ & 302 & 0.034 & 0.028 to 0.041 & 37 & 0.003 & 0.002 to 0.003 \\
\hline Oil mist & $1 \mathrm{mg} / \mathrm{m}^{3}$ & 186 & 0.50 & 0.39 to 0.63 & 16 & 0.12 & 0.08 to 0.18 \\
\hline Nitrogen dioxide & $2 \mathrm{ppm}$ (ceiling value) & 80 & 0.50 & 0.4 to 0.7 & 0 & - & - \\
\hline
\end{tabular}

HS = Norwegian hygienic standards; GM = geometric mean.

${ }^{\star}$ Confidence interval of geometric mean (GM).

used to estimate the decrease in $\mathrm{FEV}_{1}$ from the predicted value for each adjusted covariate in the regression model.

The exposure data were best described by $\log$ normal distributions and were $\ln$ transformed.

\section{Results}

CLINICAL FINDINGS AND RESPIRATORY SYMPTOMS The tunnel workers and the reference group were comparable with respect to age, atopy, and smoking habits (table 1). There was an even distribution of current smokers across the age groups. The tunnel workers reported a higher prevalence of cough during the day, shortness of breath on exercise, and chest tightness and wheezing than the reference subjects (table 2). Morning cough was associated with current smoking in both groups. Other non-significant differences in symptoms between the groups are not presented in the table.

\section{LUNG FUNCTION}

FVC (\% predicted) and $\mathrm{FEV}_{1}$ (\% predicted) in the tunnel workers decreased significantly with years employed in the same job compared with other heavy construction workers (table 3). $\mathrm{FEV}_{1} \%$ and $\mathrm{FEF}_{25-75}$ (\% predicted) were decreased in the tunnel workers compared with the reference values (table 3 ). $\mathrm{FEV}_{1}$ decreased by $17 \mathrm{ml}$ for each year of exposure to tunnel work $(\mathrm{p}=0.001)$ compared with $0.5 \mathrm{ml}$ for each year of exposure in outdoor construction workers, and by $9 \mathrm{ml}$ for each pack year of cigarette consumption in tunnel workers $(p=$ 0.001 ) compared with $7 \mathrm{ml}$ in outdoor heavy construction workers $(\mathrm{p}=0.08$; table 4$)$. The prevalence of COPD was $14 \%$ in the tunnel workers and $8 \%$ in the reference subjects $(\mathrm{p}=$ 0.03). Adjusted odds ratios for COPD are given in table 5. Only two of 212 tunnel workers and five of 205 construction workers reported asthma.

\section{CHEST RADIOGRAPHS}

None of the tunnel workers had radiological signs of silicosis. One subject who had a history of asbestos exposure had pleural plaques.

\section{EXPOSURE CHARACTERISATION}

The results of the exposure measurements are summarised in table 6 . The tunnel workers had a higher geometric mean exposure to total dust and respirable dust than the reference subjects. They were also exposed to significantly higher levels of $\alpha$-quartz, oil mist, and $\mathrm{NO}_{2}$. Exposure to particles in the tunnels showed high variability. The highest eight hour time weighted averages ( $8 \mathrm{~h}$ TWA) were: total dust $55.9 \mathrm{mg} / \mathrm{m}^{3}$, respirable dust $9.3 \mathrm{mg} / \mathrm{m}^{3}$, $\alpha$-quartz $1.98 \mathrm{mg} / \mathrm{m}^{3}$, and oil mist $4.4 \mathrm{mg} / \mathrm{m}^{3}$. The tunnel workers were periodically exposed to high concentrations of $\mathrm{NO}_{2}$ (peak value $48.5 \mathrm{ppm}$ ). The highest levels of exposure were measured when the tunnel workers passed through the blast cloud during transportation of the blasted mass. High concentrations of $\mathrm{NO}_{2}$ were also measured during loading of the blasted rock onto diesel powered trucks (1.86 ppm, $8 \mathrm{~h}$ TWA (ceiling value $2 \mathrm{ppm}$, Norway, 1998)).

\section{Discussion}

Both the annual loss of $\mathrm{FEV}_{1}$ related to exposure and the prevalence of COPD were higher in the tunnel workers than in the reference group. The prevalence of COPD in the reference group ( $8 \%$ ) was also higher than that found in the general population $(5.4 \%) .{ }^{19}$ This may be explained by the fact that outdoor construction workers (our reference group) are also exposed to dust and oil mist, although to a lower degree than the tunnel workers. The adjusted annual difference in $\mathrm{FEV}_{1}$ associated with each year of tunnel work exposure $(17 \mathrm{ml} /$ year) was four times higher than that found in Norwegian men exposed to $\alpha$-quartz $(4.3 \mathrm{ml} / \mathrm{year})^{10}$ and was also higher than that observed in British coal miners $\left(7 \mathrm{ml} /\right.$ year) ${ }^{26}$ and South African gold miners (9 ml/year).$^{27} \mathrm{In}$ the Norwegian study tunnel workers comprised only $5 \%$ of the subjects who had been exposed to $\alpha$-quartz. ${ }^{10}$ Tunnel workers are not only exposed to dust but also to considerable amounts of diesel exhaust and $\mathrm{NO}_{2}$. Our findings may indicate that this combined exposure has an effect on the airways that is worse than the effect of dust exposure alone. The observed adjusted effect from cigarette smoking on $\mathrm{FEV}_{1}$ ( $9 \mathrm{ml} /$ pack years) was almost identical to that observed in previous cross sectional studies in Norway, South Africa, and the USA. ${ }^{102628}$ The absence of radiological pathology in the tunnel workers excludes the possibility that the accelerated rate of decrease in $\mathrm{FEV}_{1}$ should be caused by silicosis. Other studies, mainly among coal and gold miners, have also indicated an association between moderate to high levels of exposure to $\alpha$-quartz and a reduction in $\mathrm{FEV}_{1}$ in the absence of radiological findings. ${ }^{26} 27$

Surveillance data on the incidence and prevalence of respiratory disease among construction workers are limited ${ }^{29}$ but some studies have suggested an increased risk of emphysema and chronic bronchitis. ${ }^{89}$ In the 
Zutphen study Heederik et al found an increased prevalence of respiratory symptoms among construction workers and an increased incidence of "chronic non-specific lung disease". 30 However, that study did not differentiate between the various subgroups of construction workers as we have done in our study.

Compared with the reference group, the tunnel workers had a significantly higher exposure to total and respirable dust, $\alpha$-quartz, oil mist, and $\mathrm{NO}_{2}$. Exposure to dust in the tunnels was periodically higher than the Norwegian hygienic standards which are $10 \mathrm{mg} / \mathrm{m}^{3}$ for total dust, $5 \mathrm{mg} / \mathrm{m}^{3}$ for respirable dust, and $0.1 \mathrm{mg} / \mathrm{m}^{3}$ for $\alpha$-quartz ( $8 \mathrm{~h}$ TWA, Norway, 1998). Exposure to $\mathrm{NO}_{2}$ was in some situations 25 times higher than the threshold value (2 ppm, Norway, 1998). Since all these components were observed in significantly higher levels in the tunnel workers than in the reference group, it is impossible to distinguish between the various pollutants with respect to detrimental effects on the airways.

The observed relationship between exposure in tunnel work and airways dysfunction may have been biased by several factors. Firstly, selection bias may have affected our results. Previous studies have shown that individuals who choose to enter dusty professions have better lung function than those who do not (primary health selection). ${ }^{32}$ To avoid a healthy worker selection bias we chose a reference group that was comparable to the study group with respect to education, socioeconomic status, selection for employment, working schedule, and work organisation. The two groups of workers were also comparable with respect to age, height, and smoking habits. Thus, if primary health selection had occurred, it had probably occurred both in the study group and in the reference group. The fact that FVC was above $100 \%$ predicted in both groups may support this notion. Also, outdoor construction workers are exposed to dust and oil mist, but at lower levels than tunnel workers. We therefore believe that the observed differences in respiratory symptoms and airflow limitation between the tunnel workers and the outdoor construction workers reflect differences in work exposure.

The cross sectional design of the study may have led to an underestimation of the effects of exposure because sensitive employees might have left the occupation. The workforce studied in cross sectional surveys can therefore be regarded as the "survivors" in the trade. The low prevalence of asthma (1-2.5\%) points in the same direction and may indicate a strong "healthy worker effect" among heavy construction workers in general.

We were not able to estimate individual cumulative exposure in the tunnel workers. The assessment of exposure was task based both in tunnel work and construction work, but in the assessment of respiratory health effects the workers were assigned to groups based on job title (tunnel worker versus construction worker) without information on the individual job tasks performed.
Levels of exposure in the tunnels showed large variability, which is probably related to performances of different job tasks. ${ }^{33}$ Variation in exposure will depend on variation in work intensity and location within the tunnel. Factors such as fan capacity, tunnel length, condition of the ventilation duct, distance from the end of the duct to the blasting area, and disturbances in the air streams may all influence the pollution levels in different parts of the tunnel. Because of these variations we found it necessary to carry out exposure assessments in all the construction sites ( $\mathrm{n}$ $=15$ ) to estimate the (geometric) mean exposure.

Diesel exhaust and the blast cloud both contain gases and particles with complex and varying composition. A study has shown that acute, short term exposure to diesel exhaust produces a pulmonary inflammatory response in healthy human volunteers. ${ }^{11}$ In healthy subjects exposure to $2 \mathrm{ppm} \mathrm{NO}$ for four hours has been shown to cause neutrophilic inflammation in the airways. ${ }^{34} \mathrm{~A}$ study of machine shop workers concluded that occupational asthma due to oil mists was common, ${ }^{14}$ and exposure to $\alpha$-quartz has been shown to be an independent predictor for spirometric airflow limitation. ${ }^{10}$ Thus, the observed effects on the airways in tunnel workers in the present study may reflect a combined exposure to several components with a similar outcome.

In conclusion, exposure to dust, $\mathrm{NO}_{2}$ and oil mist from diesel exhaust and blasting seems to enhance the risk for respiratory symptoms and COPD in tunnel workers compared with other heavy construction workers.

The authors thank the workers for participating in the study. They wish to acknowledge Dr Arne Borgersen, Majorstua Radiological Institute, Oslo, Norway for carrying out the ILO classification and Professor Tor Norseth, Dr Wijnand Eduard and Dr Helge Kjuus, National Institute of Occupational Health, Oslo, Norway for valuable advice.

Funding: The project received financial support from the Working Environment Fund of the Confederation of Norwegian Business and Industry.

1 Soestrand P, Lian K, Myran T. The contribution of inorganic gases from diesel exhaust and from the blasting cloud during excavation of a tunnel. Occup Hyg 1997;4:113 .

2 Wong PH, Phoon WH, Tan KT. Industrial hygiene aspects of tunnelling work for the mass rapid transit system in Singapore. Appl Ind Hyg 1988;3:240-3.

3 Steiner WE. Guadalope corridor transportation project asbestos health risk assessment. Sci Total Environ 1990;93: $115-24$.

4 Buskin SE, Paulozzi LI. Fatal injuries in the construction industry in Washington State. Am F Ind Med 1987;11:45360 .

5 Holmstroem E, Moritz U, Engholm G. Musculoskeletal disorders in construction workers. Occup Med: State of Art orders in construction wo
Reviews 1995;10:295-312.

6 Wahlberg JE. Health screening for occupational skin diseases in building workers. Berufsdermatosen 1969,17: $184-98$

7 Burkhart G, Schulte PA, Robinson C, et al. Job tasks, potential exposures, and health risks of laborers employed in the construction industry. Am F Ind Med 1993;24:413-25.

8 Sullivan PA, Bang KM, Hearl FJ, et al. Respiratory disease risks in the construction industry. Occup Med: State of Art Reviews 1995;10:313-34

9 Petersen JS, Zwerling C. Comparison of health outcomes among older construction and blue-collar employees in the United States. Am f Ind Med 1998;34:280-7.

10 Humerfelt S, Eide GE, Gulsvik A. Association of years of occupational quartz exposure with spirometric airflow limitation in Norwegian men aged 30-46 years. Thorax 1998;53:649-55.

11 Blomberg A. Inflammatory and antioxidant responses in the airways to oxidative and particulate air pollution. Doctor dissertation. Umeå: University of Umeå. 
12 Ulfvarson U, Alexandersson $\mathrm{R}$, Dahlquist $\mathrm{M}$, et al. Pulmonary function in workers exposed to diesel exhausts: the

13 Frampton MW, Morrow PE, Cox C, et al. Effects of nitrogen dioxide exposure on pulmonary function and airway reactivity in normal humans. Am Rev Respir Dis 1991, 143:522-7

14 Robertson AS, Weir DC, Sherwood Burge P. Occupational asthma due to oil mists. Thorax $1988 ; 43: 200-5$.

15 Kongerud J, Groennesby JK, Magnus P. Respiratory symptoms and lung function of aluminium potroom workers. Scand $\mathcal{F}$ Work Environ Health 1990;16:270-7.

16 Melbostad E, Eduard W, Magnus P. Chronic bronchitis in farmers. Scand f Work Environ Health 1997;23:271-80.

17 Kongerud J, Vale JR, Aalen OO. Questionnaire reliability and validity for aluminium potroom workers. Scand $\mathcal{F}$ Work Environ Health 1989;15:364-70.

18 Bakke PS, Baste V, Hanoa R, et al. Prevalence of obstructive lung disease in a general population: relation to occupalung disease in a general population: relation to occupational title and exp

19 Bakke P, Gulsvik A, Eide GE, et al. Smoking habits and lifetime occupational exposure to gases or dusts, including Work Environ Health 1990;16:195-202.

20 American Thoracic Society. Standardization of spirometry: 1987 update. Am Rev Respir Dis 1987;136:1285-98.

21 Quanjar PH, Tammeling GJ, Cotes JE. Standardized lung function testing. Eur Respir f 1993;10:1683-93.

22 Eriksson NE. Allergy screening with Phadiatop and CAP Phadiatop in combination with a questionnaire in adults with asthma and rhinitis. Allergy 1990;45:285-92.

23 Guidelines for the use of ILO international classification of radiographs of pneumoconiosis. Revised edition. Geneva: International Labour Office, 1980.
24 Hosmer DW, Lemeshow S. Applied logistic regression. Chichester: John Wiley, 1989.

25 Box GEP, Hunter WG, Hunter JS. Statistics for experimenters. Chichester: John Wiley, 1978

26 Marine WM, Gurr D, Jacobsen M. Clinically important respiratory effects of dust exposure and smoking in British coalminers. Am Rev Respir Dis 1988;137:106-12.

27 Cowie RL, Mabena SK. Silicosis, chronic airflow limitation, and chronic bronchitis in South African gold miners. Am Rev Respir Dis 1991;143:80-4.

28 Dockery DW, Speizer FE, Ferris Jr BG, et al. Cumulative and reversible effects of lifetime smoking on simple tests of lung function in adults. Am Rev Respir Dis 1988;137:28692.

29 Pham QT, Benis AM, Mur AM, et al. Follow-up study of construction workers with obstructive lung disease. Scand $\mathcal{F}$ Respir Dis 1977:58:215-26.

30 Heederik D, Kromhout H, Kromhout D. Relations between occupation, smoking, lung function, and incidence and mortality of chronic non-specific lung disease: the Zutphen study. Br f Ind Med 1992;49:299-308.

31 Heederik D, Pouwels H, Kromhout H, et al. Chronic non-specific lung disease and occupational exposures estimated by means of a job exposure matrix: the Zutphen study. Int f Epidemiol 1989;18:382-9.

32 Kauffmann F, Drouet D, Lellouch J, et al. Occupational exposure and 12-year spirometric changes among Paris area workers. Br f Ind Med 1982;39:221-32.

33 Eduard W, Bakke B. Experiences with task-based exposure assessment in studies of farmers and tunnel workers. Norwegian F Epidemiol 1999;9:29-34.

34 Blomberg A, Krishna MT, Bocchino V, et al. The inflammaory effects of $2 \mathrm{ppm} \mathrm{NO}_{2}$ on the airways of healthy subjects. Am f Respir Crit Care Med 1997;156:418-24. 